\title{
Physiological consequences of exposure to salinized roadside ponds on wood frog larvae and adults
}

\author{
Emily M. Hall ${ }^{\text {a,* }}$, Steven P. Brady ${ }^{b}$, Nichole M. Mattheus ${ }^{c}$, Ryan L. Earley ${ }^{c}$, Molly Diamond ${ }^{\text {a }}$, Erica J. Crespi ${ }^{\text {a }}$ \\ a School of Biological Sciences, Washington State University, Pullman, WA 99163, United States \\ b School of Forestry \& Environmental Studies, Yale University, New Haven, CT 05611, United States \\ c Department of Biological Sciences, University of Alabama, Tuscaloosa, AL 35487, United States
}

\section{A R T I C L E I N F O}

\section{Article history:}

Received 20 September 2016

Received in revised form 22 December 2016

Accepted 6 February 2017

Available online 16 February 2017

\section{Keywords:}

Amphibian

Roads

De-icing road salt

Local adaptation

Stress

Corticosterone

\begin{abstract}
A B S T R A C T
Aquatic organisms living adjacent to roads face many challenges posed by exposure to toxic runoff. The use of deicing road salt across northern latitudes has salinized nearby freshwater habitats. Freshwater amphibians exposed to road salt at early life stages typically experience reduced survival; however, few studies address laterlife effects. One study investigating whether populations can adapt to roadside ponds found survival in wood frog embryos raised in roadside environments was lowest in individuals with parents from roadside ponds. We investigated whether this negative response is also exhibited in late larval stages in reciprocally transplanted individuals from roadside populations and those located away from roads ('woodland' populations). We found reduced growth rates and more variable developmental rates in larvae raised in roadside ponds relative to woodland ponds regardless of origin, but no difference in survival between rearing environments. Laboratory exposure to road salt at relevant concentrations ( $0.6 \mathrm{ppt}$ salinity) reduced larval activity and foraging behaviors, which may explain slower growth observed in the transplant experiment. Physiological assays of adult males migrating to breed revealed increased water retention in roadside populations. Further, these bloated males exhibited elevated resting plasma corticosterone levels and reduced capacity to secrete corticosterone when stimulated. Potential fitness consequences, such as reduced longevity and fecundity post metamorphosis through adulthood, of the roadside habitat could affect wood frog demography. Taken together, we provide evidence that the conditions experienced in the roadside environment pose challenges across life stages that have implications for persistence if populations are challenged with further stressors.
\end{abstract}

(c) 2017 Elsevier Ltd. All rights reserved.

\section{Introduction}

The global road network has expanded rapidly over the last halfcentury and is projected to increase 60\% by 2050 (Dulac, 2013). Roads induce a suite of ecological consequences including roadkill, habitat fragmentation, noise disruption, and contamination of adjacent habitats (Forman and Alexander, 1998; Tennessen et al., 2014; Trombulak and Frissell, 2000). In northern latitudes of the United States the salinization of freshwater habitats due to runoff of de-icing salts is of particular concern (Jackson and Jobbagy, 2005). The intensity of this salinization can be severe, with some road-adjacent wetlands seeing salinity levels $25 \%$ that of seawater (Kaushal et al., 2005). Moreover, increases in salinity equivalent to $1 \%$ seawater can affect physiological processes of freshwater organisms and the structure of biological communities (Findlay and Kelly, 2011).

Because of their apparent narrow physiological tolerance to osmotic change, amphibians have received considerable attention in the study of

\footnotetext{
* Corresponding author.

E-mail address: emily.m.hall@wsu.edu (E.M. Hall).
}

the effects of de-icing salt runoff on wildlife. Many experimental studies show reduced embryonic and hatchling survival, growth, or developmental rates following exposure to elevated salinity levels (see review in Hopkins and Brodie, 2015). Based on these findings, demographic models predict that roadside populations have a higher probability of experiencing declines (Karraker et al., 2008); but as these and other authors (Dananay et al., 2015) point out, higher embryonic mortality could also reduce density and therefore, elevated salinity could positively affect fitness traits like size at metamorphosis. Fewer studies, however, quantify physiological effects across life stages in natural populations affected by roadside runoff (e.g., Karraker et al., 2008).

Although many amphibian species have adapted to coastal brackish environments, the energetic cost of osmoregulation is hypothesized to be significant, especially for embryonic life stages with limited osmoregulatory tolerances (Hopkins and Brodie, 2015). As larvae develop, they accrue physiological adaptations to elevated salinity (i.e., internal gills and integumentary ion pumps), however, increased tolerance comes at the cost of size and time to metamorphosis (Gomez-Mestre et al., 2004; Kearney et al., 2014). Additionally, road salt effects of the larval environment can carry over to juvenile stages (Dananay et al., 
2015), and juveniles and adults are exposed to de-icing salt runoff in breeding ponds or the surrounding forests (Findlay and Kelly, 2011). Therefore, continual exposure over life stages could pose osmoregulatory challenges that decrease survival, reproductive success, and physiological health of adults, and in turn, affect offspring performance mediated by parental environmental effects (Galloway, 2001).

In addition to the proximate impacts, it is important to consider the evolutionary responses of roadside populations. Strong selective pressures derived from recent environmental change have been observed to cause rapid evolutionary responses (Hendry et al., 2008; Sih et al., 2011). In the case of road runoff, selection imposed by osmotic changes can lead to differentiation of local populations in their capacity to tolerate increased salinity, as seen in the spotted salamander (Brady, 2012) and amphibians that inhabit brackish wetlands in coastal areas (e.g., Gomez-Mestre and Tejedo, 2003). Alternatively, populations could respond maladaptively, where fitness is reduced in their natal environment, a phenomenon that may be emerging as a result of rapid environmental change (Rolshausen et al., 2015). In order to predict population responses to recent environmental change, better estimates of the evolutionary and physiological capacities of natural populations are needed.

Here, we assessed the physiological responses to road salt runoff across life history stages of the wood frog (Lithobates sylvaticus) in natural populations adjacent to roads that receive road salt application and those distant from roads (hereafter 'woodland ponds'). Brady (2013) showed that wood frog hatchlings grow, develop, and survive at lower rates in roadside ponds with elevated salinity compared to woodland ponds and hatchlings from parents collected from roadside ponds experienced lower survival compared to those with parents from woodland ponds when reared in roadside ponds. This survival disadvantage suggests that they are locally maladapted to their environment or there are negative parental environmental effects. To extend these findings, using the same populations we first conducted a reciprocal transplant experiment in which individuals with parents collected from roadside or woodland environments were reared in either environment type. We hypothesized that traits expressed later in development are influenced by local adaptation or parental environmental effects resulting from exposure to the roadside habitat. Second, we conducted a laboratory experiment to test the hypothesis that road salt exposure alters activity and foraging behavior, as shown in the context of other environmental stressors (Crespi and Denver, 2004; Fraker et al., 2009). Further, it has been shown that these behaviors can contribute to growth or developmental rates (Anholt and Werner, 1998; Skelly and Werner, 1990), providing a potential mechanism of responses seen in the field. Finally, we collected adults migrating to breed in roadside and woodland ponds to test the hypothesis that roadside environments are linked to elevated physiological stress in breeding adults.

\section{Methods}

\subsection{Study organism and region}

Wood frogs are widely distributed throughout eastern North America and much of Canada (Martof and Humphries, 1959). We conducted our study in Northeast Connecticut in or near Yale Myers Experimental Forest, a managed mixed-hardwood forest in which roads and rural development are the primary anthropogenic features (Fig. 1). Road salt is applied on these paved roads and conductivities of adjacent ponds are known to reach $4000 \mu \mathrm{s} / \mathrm{cm}$ (Brady, 2013). Wood frogs migrate to breeding ponds in early spring, and in some populations site fidelity is nearly $100 \%$ among adults and $80 \%$ in juveniles (Berven and Grudzien, 1990); and there are phenotypically differentiated populations along environmental gradients that span tens to hundreds of meters at this site (e.g., canopy cover; Skelly, 2004).

\subsection{Reciprocal transplant experiment}

\subsubsection{Site selection}

We chose 4 ponds with high conductivity ( $>400 \mu \mathrm{s} / \mathrm{cm}$ at the time of breeding) within $20 \mathrm{~m}$ of a paved road (i.e., roadside), and 4 ponds that were located $>200 \mathrm{~m}$ from a paved road (i.e., woodland; see Fig. 1). We used ponds with a breeding population in excess of 10 wood frog pairs so we would not dramatically affect populations. We matched roadside and woodland ponds based on similar canopy cover, pool size, and emergent vegetation, resulting in 4 reciprocally transplanted pairs of populations (see Table 1 for site characteristics). Of the abiotic variables we monitored each month throughout the four months of the experiment, only conductivity (a measure of salinity) differed between environment types (repeated-measures analysis of variance [ANOVA]; $\mathrm{df}=1, \mathrm{~F}=368.47, \mathrm{P}<0.001$ ). Specifically, salinity levels were $>20$ times higher on average (maximum of $2100 \mu \mathrm{s} / \mathrm{cm}$ or $\sim 1.07 \mathrm{ppt}$ ) in roadside ponds compared to woodland ponds. This maximum concentration is nearing the concentration predicted to cause extirpation of this species $(3000 \mu \mathrm{s} / \mathrm{cm}$; Karraker et al., 2008), which was evident by little to no activity of wood frogs in the extremely high salinity ponds in our study region (EMH pers. obs.).

\subsubsection{Adult collection and breeding}

We captured adults migrating into ponds with drift fencing at each of the 8 ponds; males and females from each pond were haphazardly paired and housed in a clear, $5 \mathrm{~L}$ container filled with $\sim 1 \mathrm{~L}$ of water beside the pond from which they were collected (Apr. 8-15, 2011). Oviposition occurred within 2-11 d of pairing, and eggs from 4 pairs/pond were divided and assigned to treatment groups. Eggs were exposed to pond water for up to $48 \mathrm{~h}$, although this has been shown to have no effect on embryonic survival, growth or developmental rates (Brady, 2016), this early exposure may affect larval vital traits. Protocols were approved by the Institutional Animal Care and Use Committee (IACUC) of Yale University (201111024) and collections were approved by the Connecticut Department of Energy and Environmental Protection (CDEEP Scientific Collections Permit \#1115003).

\subsubsection{Experimental design}

We conducted reciprocal transplants between each of the 4 pairs of roadside and woodland pools (see Appendix A: Supplementary Fig. 1 for diagram). We split clusters of $\sim 100$ embryos from each egg mass into floating $14 \mathrm{~L}$ plastic enclosures in both the natal pond and the reciprocal pond of opposite type. We used a subset of individuals that were measured for embryonic traits in Brady (2013). At feeding stage (Gosner stage 25 [Gosner, 1960]) we transferred larvae into larger enclosures ( $n=5$ larvae/replicate enclosure/clutch) in the same pond, which were $0.5 \mathrm{~m}$ diameter $\times 1 \mathrm{~m}$ tall cylinder made of no-see-um mesh $(20 \times 20$ gauge $)$, submerged with $>20 \mathrm{~cm}$ above water level, and $4 \mathrm{~L}$ of dry leaves to provide substrate for algae growth. We had a total of 16 enclosures in each pond ( 2 replicates/clutch $\times 4$ clutches $\times 2$ origins), except two cases in which hatchling survival was low: one woodland pond had 3 natal and 4 reciprocal enclosures, and one roadside pond had 4 natal and 8 reciprocal enclosures.

At the start and end (after 20-21 d; June 17-23, 2011) of this experiment, we photographed each individual with a ruled scale and recorded Gosner stage and snout-vent length (SVL) using Image JV1.44p (Rasband 1997-2012). We measured percent survival, and calculated growth and developmental rates as the exponential functions of change in SVL or stage over of days elapsed (e.g., [ln(final size) - $\ln ($ initial size $)]$ / period).

\subsubsection{Statistical analysis}

We analyzed data using R, V. 3.0.2 (R Development Core Team, 2012). We used a logistic regression combined with MCMC 


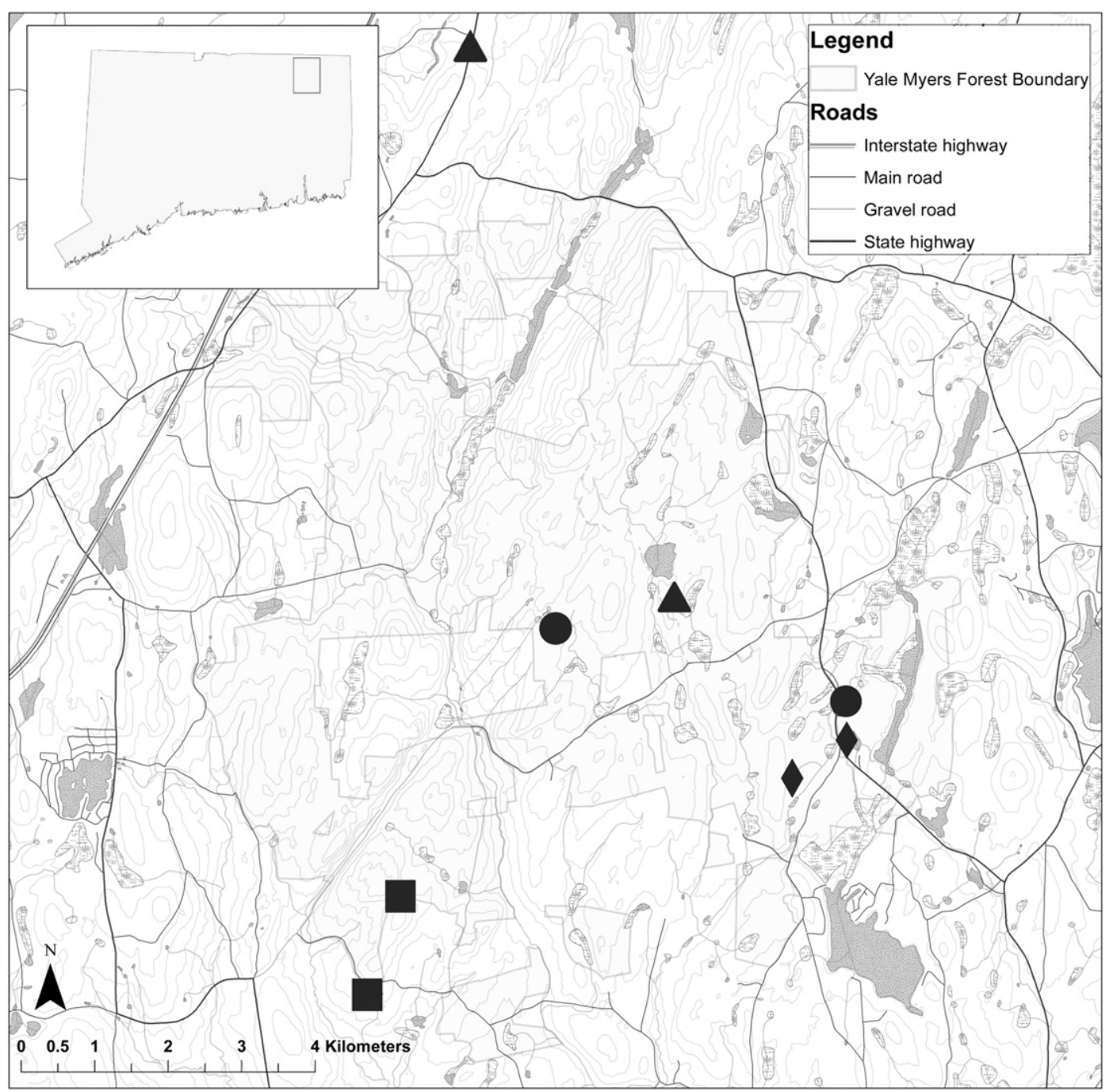

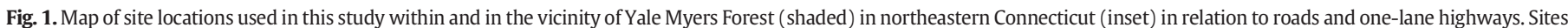

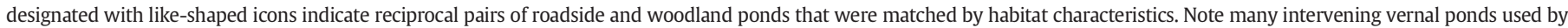
wood frogs are not shown on this map.

randomization methods ( $M C M C g l m m$ function in the package MCMCglmm; Hadfield, 2010) to determine differences in survival (proportion remaining at the end of the experiment) between parental origin and rearing environment types, and the interaction of the two (using the "multinomial2" family for a binomial distribution, following Brady, 2012), and the highest probability density interval (HPD). We analyzed growth and developmental rates (mean per enclosure) with survival as a covariate, and variance in mean developmental stage between cages (coefficient of variation) with mixed linear models run by the function lmer (package lme4; Bates et al., 2015) after testing for heteroscedasticity. We evaluated these models using the summary function in the lmerTest package (Kuznetsova et al., 2013), which estimates P-values based on Satterthwaite's approximations. In all models, we included reciprocal pair (matched roadside and woodland ponds) and egg clutch as random effects, and survival in the enclosure as a fixed covariate. We first analyzed the interaction of parental origin type and the rearing environment as fixed effects, then if the interaction effect was not significant we refit with main effects alone. We also were interested in whether the relationship between growth rate and developmental rate per enclosure differed and used a mixed linear model of growth rate by developmental rate interacting with either origin or environment type, with the same random effects as above.

\subsection{Laboratory road salt-exposure experiment}

\subsubsection{Experimental design}

To examine the specific effects of salt exposure on larval growth, development and behavior, 3 egg masses were collected from one roadside pond (not used in reciprocal study) within 4 days after being laid. We rinsed eggs with tap water dechlorinated with Novaqua Plus water conditioner (Kordon, Hayward, CA, USA), and divided each clutch into either fresh water or road salt treated aquaria housed in an animal room at $21 \pm 3{ }^{\circ} \mathrm{C}$ in a $15 \mathrm{~L}: 9 \mathrm{D}$ light cycle at the University of Connecticut (Storrs, CT). The road salt treatment was created by mixing road salt obtained from the Connecticut Department of Transportation (sodium chloride; Union, $\mathrm{CT}$ ) with dechlorinated tap water to a specific conductance of $1200 \mu \mathrm{s} / \mathrm{cm}$ ( 0.6 ppt salinity; approximating the maximum found in roadside ponds where wood frogs breed in this region, and below the maximum found in other regions [i.e., $1968 \mu \mathrm{s} / \mathrm{cm}$ in Ontario; Sanzo and Hecnar, 2006]); conductivity of treated tap water was $\sim 150 \mu \mathrm{s} / \mathrm{cm}$. Water was changed weekly throughout the experiment (maintaining conductivity and effectively reducing nitrate and ammonia levels). At Gosner stage 25, 60 individuals were haphazardly assorted into 5 replicate $10 \mathrm{~L}$ aquaria containing $7 \mathrm{~L}$ of their respective treatment, fresh or road salt treated water; each housing 6 larvae, 
Table 1

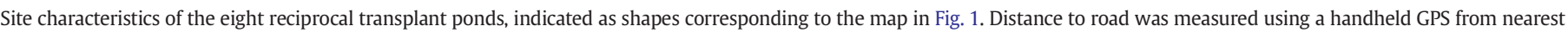

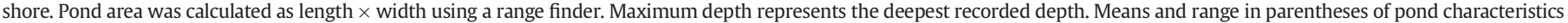

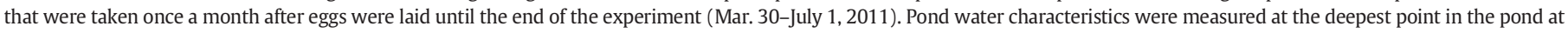

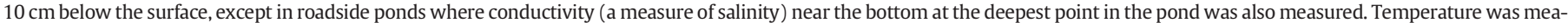

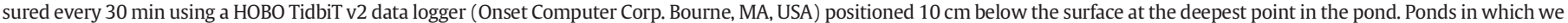
compared adult physiological health are indicated with an asterisk $\left({ }^{*}\right)$.

\begin{tabular}{|c|c|c|c|c|c|c|c|c|c|}
\hline Pond type & $\begin{array}{l}\text { Reciprocal } \\
\text { transplant pair }\end{array}$ & $\begin{array}{l}\text { Distance to } \\
\operatorname{road}(\mathrm{m})\end{array}$ & $\begin{array}{l}\text { Pond Area } \\
\left(\mathrm{m}^{3}\right)\end{array}$ & $\begin{array}{l}\text { Maximum } \\
\text { depth }(\mathrm{cm})\end{array}$ & $\begin{array}{l}\text { Conductivity near } \\
\text { surface }(\mu \mathrm{s} / \mathrm{cm})\end{array}$ & $\begin{array}{l}\text { Conductivity near } \\
\text { bottom }(\mu \mathrm{s} / \mathrm{cm})\end{array}$ & DO (mg/L) & $\mathrm{pH}$ & $\begin{array}{l}\text { Water } \\
\text { temperature } \\
\left({ }^{\circ} \mathrm{C}\right)\end{array}$ \\
\hline \multirow[t]{5}{*}{ Roadside } & Diamond* & 1 & 4740 & 82 & $1042(868-1200)$ & 1466 (963-2100) & $\begin{array}{l}2.33 \\
(0.58-4.35)\end{array}$ & $\begin{array}{l}4.95 \\
(4.70-5.35)\end{array}$ & $13.4(4.9-19.5)$ \\
\hline & Square* & 2 & 467 & 160 & $404.25(265-635)$ & $881(263-1176)$ & $\begin{array}{l}3.93 \\
(1.56-7.70)\end{array}$ & $\begin{array}{l}5.74 \\
(5.22-6.03)\end{array}$ & $13.6(6.1-22.9)$ \\
\hline & Triangle* & 15 & 1060 & 81 & $384.5(283-440)$ & $437(286-600)$ & $\begin{array}{l}6.56 \\
(3.43-9.00)\end{array}$ & $\begin{array}{l}5.78 \\
(5.31-6.40)\end{array}$ & $13.1(3.7-22.5)$ \\
\hline & Circle & 20 & 1028 & 107 & $950(500-1420)$ & 1395 (979-2000) & $\begin{array}{l}4.11 \\
(0.75-8.40)\end{array}$ & $\begin{array}{l}5.51 \\
(4.87-5.83)\end{array}$ & $13.0(4.1-20.1)$ \\
\hline & Average & 9.5 & 1823 & 108 & 695 & 1045 & 4.23 & 5.50 & 13.3 \\
\hline \multirow[t]{5}{*}{ Woodland } & Diamond* & 238 & 3570 & 83 & $42.9(38-50.7)$ & - & $\begin{array}{l}3.69 \\
(1.12-5.23)\end{array}$ & $\begin{array}{l}5.89 \\
(5.38-6.29)\end{array}$ & $13.7(4.8-19.9)$ \\
\hline & Square & 686 & 561 & 81 & $32.5(31-35)$ & - & $\begin{array}{l}4.75 \\
(1.13-7.73)\end{array}$ & $\begin{array}{l}5.87 \\
(5.82-6.07)\end{array}$ & $13.6(5.1-21.5)$ \\
\hline & Triangle* & 644 & 632 & 74 & $27.4(24-34)$ & - & $\begin{array}{l}3.91 \\
(1.26-5.76)\end{array}$ & $\begin{array}{l}5.39 \\
(4.90-5.68)\end{array}$ & $13.6(6.0-21.2)$ \\
\hline & Circle & 988 & 1500 & 50 & $28.5(27.5-30)$ & - & $\begin{array}{l}3.60 \\
(2.40-4.55)\end{array}$ & $\begin{array}{l}5.25 \\
(5.05-5.39)\end{array}$ & $13.2(4.5-19.7)$ \\
\hline & Average & 639 & 1566 & 72 & 32.8 & - & 3.99 & 5.6 & 13.5 \\
\hline
\end{tabular}

including 2 focal individuals marked with a visible elastomer tag along the dorsal-anterior portion of the tail (NMT INC Northwest Marine Technology, WA, USA; as described in Warne and Crespi, 2015). Individuals were observed for one week after tagging, and only individuals that were eating and active were included in the experiment. Animals were fed $0.15 \mathrm{~g}$ of algae pellets, Hikari Tropical Algae Wafers (Hikari Sales, USA, Hayward, CA) twice weekly.

For our behavioral assay, we observed focal individuals for $2 \mathrm{~min}$, 30-60 min after feeding or at the same time on days when animals were not fed (food was still present); this was repeated 6 times over a two-week period. One observer recorded the percent of time each individual spent swimming, eating, or resting using an Excel program (see Methods in Crespi and Denver, 2004). All animals were euthanized, weighed and staged on the date that the first individuals reached metamorphic climax. Protocols were approved by the Washington State University IACUC (04520-002) and collection of animals was permitted by CDEEP (\#1115003).

\subsubsection{Statistical analysis}

We used mixed model analyses after testing for heteroscedasticity (same R packages as above) to determine if differences existed between treatments in time spent exhibiting each behavior, with replicate and trial as random factors, and aquarium temperature as a fixed covariate. We also compared final developmental stage, and mass with developmental stage as a covariate only in pre-metamorphic climax $(<$ Gosner 42) larvae with replicate aquaria as a random factor in mixed models.

\subsection{Assessment of physiological condition of adult males}

\subsubsection{Experimental design}

To assess physiological differences in breeding adults, we collected a separate subset of male wood frogs at the time of migration (see above Methods; collected on Apr. 6, 2011) from 5 ponds ( 2 woodland and 3 roadside ponds, $\mathrm{n}=6-10$ per pond); females were not collected to minimize the effects on population sizes. Upon collection, we measured body mass and SVL, placed each frog in a plastic shoebox with $\sim 1 \mathrm{~cm}$ of water and leaf litter collected from their pond, and then kept outdoors overnight. This allowed frogs to return to a resting state and standardized handling before blood samples were collected for measurement of corticosterone, the primary glucocorticoid hormone in amphibians that is regulated by activity of the hypothalamo-pituitary-interrenal axis (HPI, i.e., neuroendocrine stress axis). We measured plasma corticosterone concentrations in two contexts (in separate animals): at rest ( $\mathrm{n}=13$ roadside, $\mathrm{n}=7$ woodland) as an indicator of baseline HPI axis activity (McEwen and Wingfield, 2003), and after an intraperitoneal injection of adrenocorticropic hormone ( $\mathrm{ACTH} ; \mathrm{n}=11$ roadside, $\mathrm{n}=7$ woodland) as an indicator of interrenal responsiveness (Glennemeier and Denver, 2002). Previous work in a variety of vertebrates has shown that chronically stressful conditions can cause elevated plasma corticosterone concentrations at rest (see reviews in Bonier et al., 2009; Crespi et al., 2013) or reduced interrenal responsiveness to ACTH, both resulting in reduced "reactive scope" of the HPI axis (Breuner et al., 2008; Hu et al., 2008; Romero et al., 2009). We did not include a saline-injected group (i.e., a handling control) in this study because we were limited by the number of animals we were able to sacrifice and a preliminary experiment showed that circulating corticosterone concentrations were not different between a non-handled group and a saline injected group when blood was sampled $2 \mathrm{~h}$ after injection (see Appendix A: Supplementary Fig. 2). Therefore, although handling and ACTH response are confounded in our treatment, the stress of injection likely had a negligible effect on corticosterone levels.

At approximately $0800 \mathrm{~h}$ the morning after frogs were placed in containers, we haphazardly assigned them to groups: resting frogs, which were not handled, and ACTH-induced frogs, which were given an intraperitoneal injection of $60 \mathrm{mIU} / \mathrm{g}$ porcine ACTH (Sigma A6303) (50$100 \mu \mathrm{L}$ total volume - a minute fraction of their body mass), the lowest dose that stimulated a significant increase in corticosterone in a preliminary experiment (Mattheus, 2012). We anesthetized frogs in both groups $2-4 \mathrm{~h}$ later by topically applying $20 \%$ benzocaine gel (Extrastrength Orajel; Church \& Dwight Inc., Ewing, NJ, USA) on the ventral skin and head; we then collected blood via cardiac puncture and euthanized animals by cervical dislocation. All blood samples were obtained within $5 \mathrm{~min}$ of anesthetic application. Note that temperatures were $\sim 4{ }^{\circ} \mathrm{C}$ at the time, and frogs were not as responsive to handling as they would have been at room temperature. We verified that neither time until blood collection nor time after injection were correlated with corticosterone levels, and therefore these variables were not included in statistical models. After collection, blood samples were centrifuged and the resulting plasma frozen at $-20{ }^{\circ} \mathrm{C}$ until hormone analysis. All protocols were approved by the Washington State 

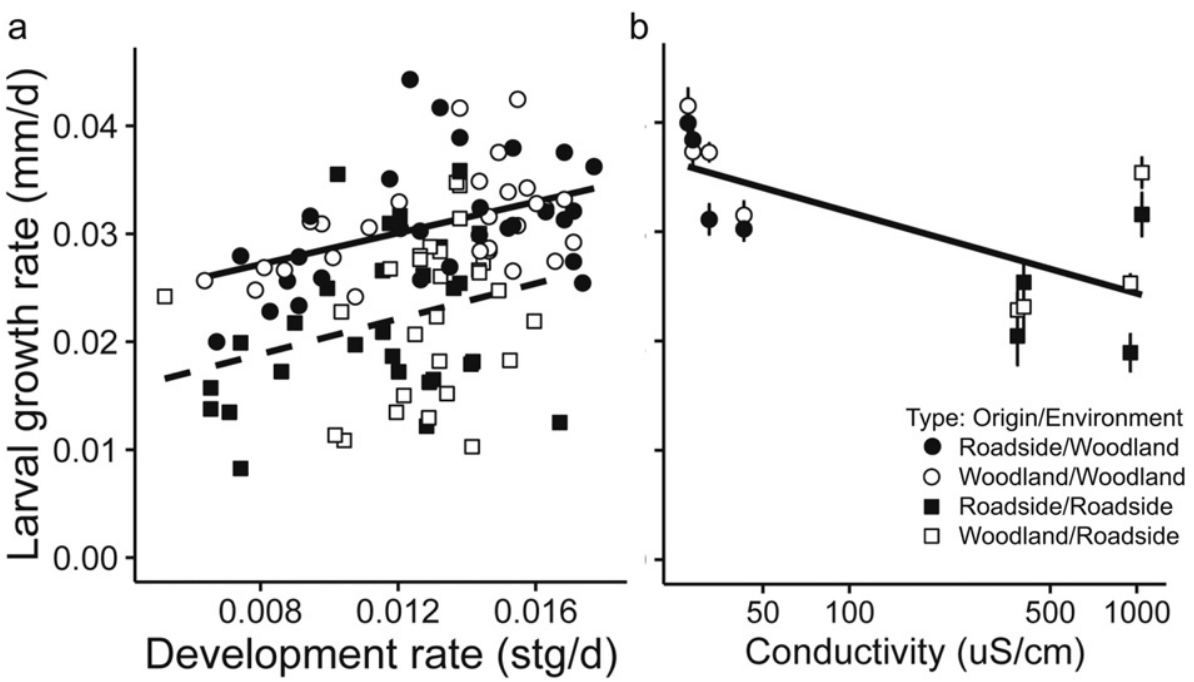

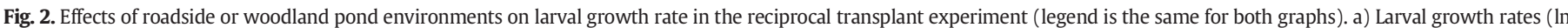

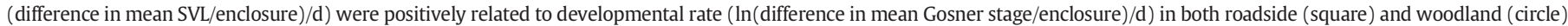

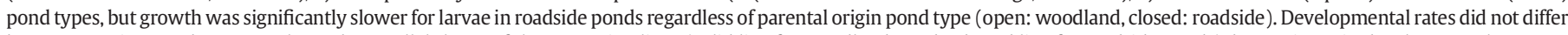

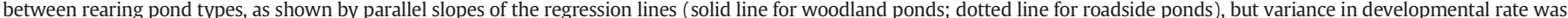

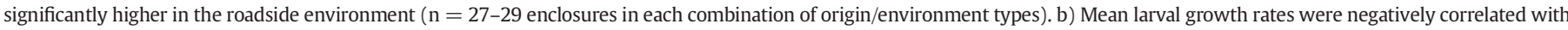

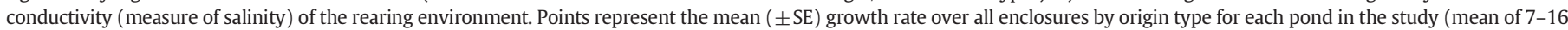
enclosures by origin type in 8 different ponds: 4 roadside and 4 woodland) and the regression line is across all means regardless of origin.

University IACUC (04167-006), and collection of animals was permitted by the CDEEP (\#1113003).

To measure corticosterone concentrations in plasma $(\mathrm{ng} / \mathrm{mL})$, we used solid phase extraction following the methods of Earley et al. (2013). We used $20 \mu \mathrm{L}$ of each sample, and diluted to 1:40-1:400 so that all samples fell within the linear range of the standard curve for the corticosterone enzyme immunoassay (Cayman Chemicals Inc., Ann Arbor, MI). We validated this assay for wood frog plasma by showing parallelism and cold-spiked samples had high recovery, as previously reported (Mattheus, 2012). Samples were randomly assigned to 9 assay plates (with others obtained for another study), with resting and ACTH-induced samples represented on each plate. Mean intra-assay coefficient of variation was $4.0 \%$ ( $\pm 0.6 \% \mathrm{SE}, 1.7-8.1 \%$ range $)$, and the inter-assay coefficient of variation was $9.6 \%$.

\subsubsection{Statistical analysis}

We compared body mass, SVL and body condition (residual of regression of body mass on SVL) between pond types (roadside or woodland) using mixed model linear regression after testing for heteroscedasticity (same $\mathrm{R}$ packages as above) of these measures, with pond as a random factor. We determined differences in resting and ACTH-induced plasma corticosterone concentrations using a mixed model with interactions between treatment and pond type, treatment and body mass residuals, and pond as a random variable. We included body mass residuals in the model due to severe water retention observed upon dissection, and glucocorticoids are known to play a role in osmoregulation.

\section{Results}

\subsection{Reciprocal transplant experiment}

Survival of wood frog larvae to Gosner stages 35-38 (just prior to metamorphic climax) in each group ranged between 85 and $89 \%$, and did not differ by rearing environment type $(\mathrm{MCMC}$ mean $=-0.531$, $95 \%$ HPD $=-1.546-0.488, \mathrm{P}=0.310$ ) or parental origin type $(\mathrm{MCMC}$ mean $=-0.242,95 \% \mathrm{HPD}=-1.27-0.677, \mathrm{P}=0.610)$. We found that growth rate was $28 \%$ lower in roadside ponds compared to those raised in woodland ponds $\left(\beta_{\text {Roadside }}=-0.009 \pm 0.002\right.$, $\left.\mathrm{t}_{47.41}=-5.363, \mathrm{P}<0.001\right)$, and higher in enclosures with greater survival $\left(\beta_{\text {Survival }}=0.008 \pm 0.003, \mathrm{t}_{92.58}=2.707, \mathrm{P}=0.008\right)$, but there was no effect of parental origin type $\left(\mathrm{t}_{48.11}=-1.103, \mathrm{P}=0.280\right)$, nor the interaction between rearing environment type and parental origin type on growth rate $\left(t_{46.41}=-0.181, \mathrm{P}=0.857\right)$. Developmental rate did not differ between rearing environment types $\left(\mathrm{t}_{46.43}=-1.074, \mathrm{P}=0.288\right)$, origin types $\left(\mathrm{t}_{45.37}=-1.259, \mathrm{P}=\right.$ $0.214)$, the interaction between the two $\left(\mathrm{t}_{44.98}=-0.856, \mathrm{P}=\right.$ $0.396)$, nor by survival $\left(t_{80.80}=1.541, P=0.127\right)$. However, the coefficient of variance (CV) in developmental stage was greater for larvae reared in roadside ponds compared to woodland ponds (CV roadside $=3.15$ and $\mathrm{CV}$ woodland $1.49 ; \beta_{\text {Roadside }}=-1.579 \pm$ $\left.0.545, \mathrm{t}_{45.99}=2.899, \mathrm{P}=0.006\right)$, but not origin type $\left(\mathrm{t}_{43.31}=\right.$ $0.797, \mathrm{P}=0.430)$, or the interaction of the two $\left(\mathrm{t}_{42.3}=0.824\right.$, $\mathrm{P}=0.415)$. We also found that growth rate was positively correlated with developmental rate among enclosures ( $\beta_{\text {Development }}=$ $0.023 \pm 0.008, \mathrm{t}_{106.7}=2.853, \mathrm{P}=0.005$, Fig. $2 \mathrm{~A}$ ) and this relationship was marginally affected by rearing environment type $\left(\beta_{\text {Interaction }}=-0.884 \pm 0.504, \mathrm{t}_{91.84}=-1.756, \mathrm{P}=0.083\right)$ and parental origin type $\left(\beta_{\text {Interaction }}=0.884 \pm 0.483, \mathrm{t}_{101.72}=1.825, \mathrm{P}=\right.$ $0.071)$. Growth rate was negatively correlated with conductivity of ponds $\left(\beta_{\text {Conductivity }}=-0.007 \pm 0.001, \mathrm{t}_{47.39}=-5.479, \mathrm{P}<0.001\right.$, Fig. 2B).

\subsection{Laboratory salt-exposure experiment}

Following 67 days of exposure to elevated salinities on par with what was measured in roadside ponds in this region, larvae approaching metamorphosis were less developed $\left(\beta_{\text {Road salt }}=-1.615 \pm 0.611\right.$, $t_{57}=-2.645, P=0.011$, Fig. $3 A$ ) but weighed more for their specific stage $\left(\beta_{\text {Road salt }}=0.003 \pm 0.001, \mathrm{t}_{51.21}=4.272, \mathrm{P}<0.001\right.$; Fig. $\left.3 \mathrm{~B}\right)$ compared to those raised in freshwater. On average, larvae raised in $1200 \mu \mathrm{s} /$ $\mathrm{cm}$ salinity were 1.62 Gosner stages less developed and had $14.9 \%$ more mass than those raised in freshwater. Also, larvae exposed to road salt spent $54.4 \%$ less time eating $\left(\beta_{\text {Road salt }}=-0.060 \pm 0.028, \mathrm{t}_{90.37}=-\right.$ $2.149, \mathrm{P}=0.034)$ and $13.9 \%$ more time resting $\left(\beta_{\text {Road salt }}=0.101 \pm\right.$ $0.041, \mathrm{t}_{89.89}=2.497, \mathrm{P}=0.014$; Fig. $3 \mathrm{C}$ ). 
a
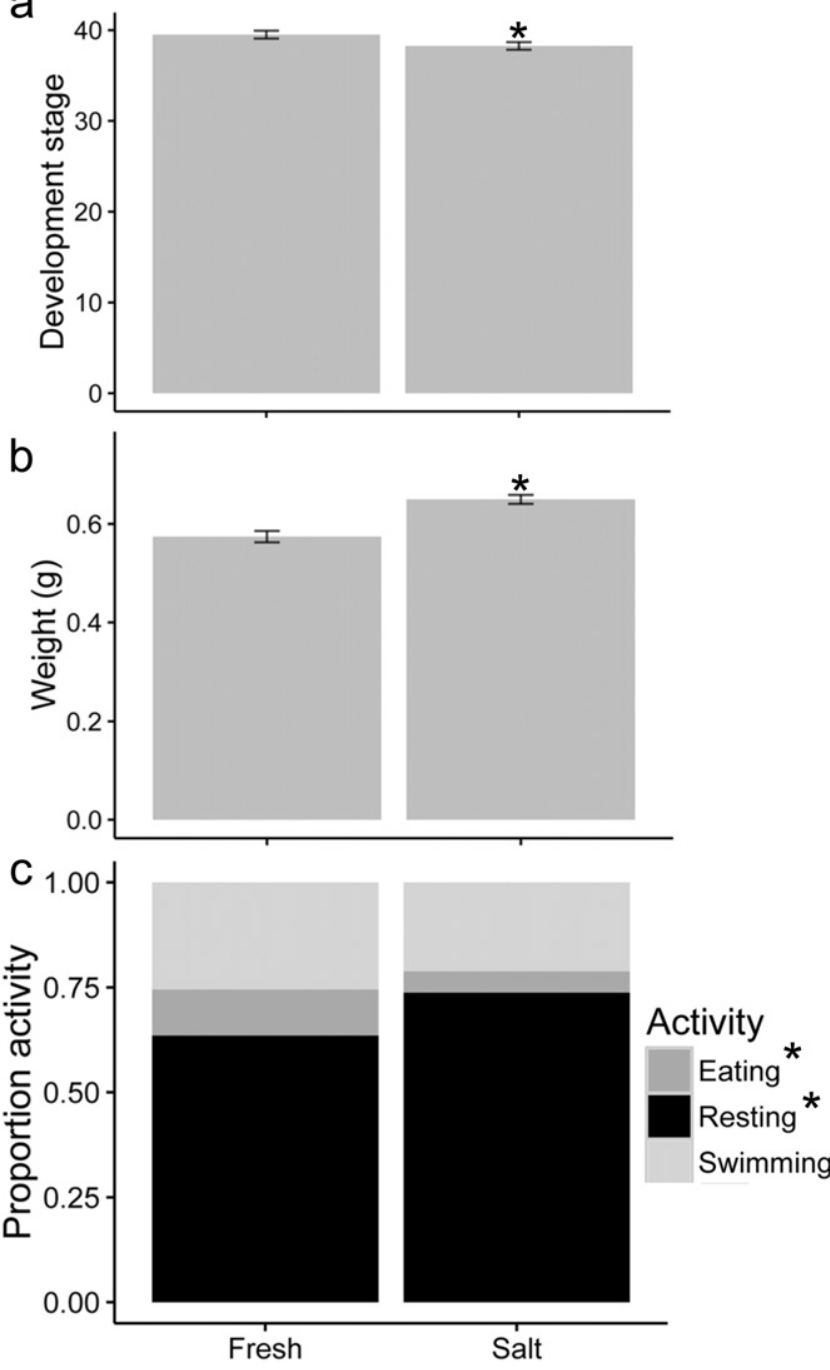

Fig. 3. Effects of elevated salinity on wood frog larvae in a laboratory experiment. a) Mean Gosner developmental stage ( \pm SE) was lower $(n=30$ per treatment), and $b)$ mean body mass $( \pm$ SE) was higher after $67 \mathrm{~d}$ of exposure to road salt treated water $(1200 \mu \mathrm{s} / \mathrm{cm}$, $\sim 0.6 \mathrm{ppt}$, near maximum found in reciprocal transplant ponds) compared to fresh water (well water, $\sim 150 \mu \mathrm{s} / \mathrm{cm}$ ); $\mathrm{n}=24$ freshwater and 27 saltwater at most stage $42 . \mathrm{c}$ ) Mean proportion of time spent resting, swimming or foraging during 2 min behavior observations (averaged over 6 trials/individual) of wood frog larvae $(n=10$ focal larvae/treatment). For all graphs, an asterisk indicates significant difference in means.

\subsection{Adult male physiology}

Males migrating to breed to roadside ponds were no different in SVL ( $n=17$ woodland, 26 roadside; $\left.\mathrm{t}_{3.0}=0.327, \mathrm{P}=0.765\right)$ or mass $(\mathrm{n}=15$ woodland, 32 roadside; $t_{3.103}=1.968, P=0.141$ ), but had greater mass for their body length compared to males migrating to woodland ponds (residuals of mass $\times$ SVL: $\mathrm{n}=15$ woodland, 26 roadside; $\beta_{\text {Roadside }}=$ $1.453 \pm 0.418, \mathrm{t}_{3.294}=3.475, \mathrm{P}=0.035$; Fig. $\left.4 \mathrm{E}\right)$. Although differences in muscle mass could contribute to variation in body condition, during dissection we observed these males had almost no fat and had more fluid in the peritoneal cavity and distended bladders relative to males returning to woodland ponds (Fig. 4C\&D). Therefore, we interpreted greater residual body mass to reflect the level of water retention (i.e., bloating or edema) exhibited by animals upon collection.

Frogs receiving the ACTH-injections had significantly higher plasma levels of corticosterone than those sampled at rest (resting mean $(\mathrm{SE})=19.86(1.18) \mathrm{ng} / \mathrm{mL}, \mathrm{ATCH}$-induced mean $(\mathrm{SE})=43.65(1.20)$ $\left.\mathrm{ng} / \mathrm{mL} ; \beta_{\text {Injection }}=0.342 \pm 0.108, \mathrm{t}_{35.99}=3.15, \mathrm{P}=0.003\right)$. The overnight housing of frogs did not cause a physiological stress response, as the resting values we measured were either similar to or below those collected from frogs within 2-3 min of capture (Swierk et al., 2014). While there was not a main effect of pond type on plasma corticosterone concentrations $\left(\beta_{\text {Interaction }}=0.295 \pm 0.229, \mathrm{t}_{32}=1.291, \mathrm{P}=\right.$ $0.206 ; \beta_{\text {Roadside }}=-0.304 \pm 0.154, \mathrm{t}_{32}=-1.969, \mathrm{P}=0.058$ ), there was a significant interaction between injection treatment and body mass residuals $\left(\beta_{\text {Interaction }}=-0.223 \pm 0.089, \mathrm{t}_{32}=-2.508, \mathrm{P}=\right.$ $0.017 ; \beta_{\text {Mass residuals }}=-0.192 \pm 0.054, \mathrm{t}_{32}=3.575, \mathrm{P}=0.001$, Fig. $4 \mathrm{~F})$. Males with greater water retention tended to have higher baseline plasma corticosterone levels, whereas ACTH-induced corticosterone levels did not vary with water retention. When both groups are compared, the interrenal glands of males with lower water retention appeared to have a greater capacity to respond to activation of the HPI axis.

\section{Discussion}

We used a combination of field and laboratory experiments to test the hypotheses that 1) similar to embryonic stages, late-stage larval vital rates (survival, growth, and development) are influenced by local adaptation or parental environmental effects resulting from a history of exposure to the roadside environment, 2) road salt exposure alters larval behaviors associated with growth rates, and 3) roadside conditions compromise adult health and capacity to respond to stress. In our reciprocal transplant experiment, we found that the roadside environment did not affect larval survival, but negatively affected growth rate regardless of origin. These results suggest that unlike hatchlings, late-stage larvae can survive salinity levels over 20 -fold higher than woodland pond conditions, but the increased energetic demand for osmoregulation reduces available resources that can be allocated towards somatic growth. Our behavioral assay suggested that reduced foraging rates might explain reduced growth observed in the transplant experiment. Slower larval growth rate could have negative fitness consequences, such as reduced post-metamorphic survival, increased time to reproductive maturity, reduced mating success and fecundity, and reduced stress responsiveness (Warne and Crespi, 2015; Wilbur and Collins, 1973), all of which could have important demographic consequences (Smith-Gill and Berven, 1979; Wilbur and Collins, 1973). The roadside environment also induced greater variability in developmental rate, which was associated with lower averages, and has been shown in wood frogs exposed to other stressors such as reduced food availability and increased density (Peacor and Pfister, 2006; Warne and Crespi, 2015). Lastly, we found that adult males migrating to breed in roadside ponds were retaining excessive amounts of water in tissues and had extended bladders. These bloated individuals had increased resting corticosterone levels and a reduced capacity of the interrenal glands to respond to ACTH stimulation, which is indicative of chronic stress (McEwen and Wingfield, 2003).

Although larvae in roadside ponds exhibited slower growth rates, the pond type of the parents or the initial exposure of eggs to pond water for $48 \mathrm{~h}$ did not affect any of the measured larval characteristics. Therefore, we did not find support for our hypothesis that late larval stages of wood frogs exhibit signs of maladaptation caused by salinized roadside environments, as shown in earlier larval stages (Brady, 2013). This finding corroborates previous work describing variation in tolerance among life stages (Kearney et al., 2014; Karraker et al., 2008), and suggests the hypothesis that the physiological capacities of late-larval stages to tolerate salinity relative to earlier stages in combination with demographic processes such as immigration might facilitate population persistence in the presence of an early survival disadvantage in these roadside environments. The salinities in our experimental ponds (265-1420 $\mu \mathrm{s} / \mathrm{cm}$ at the surface) may not be high enough to exert selective pressure on later stage larvae, and therefore, would not cause evolutionary change in traits exhibited at this life history stage. In addition, our study ponds are within a large matrix of vernal ponds in which wood frogs breed, which may offer enough gene 


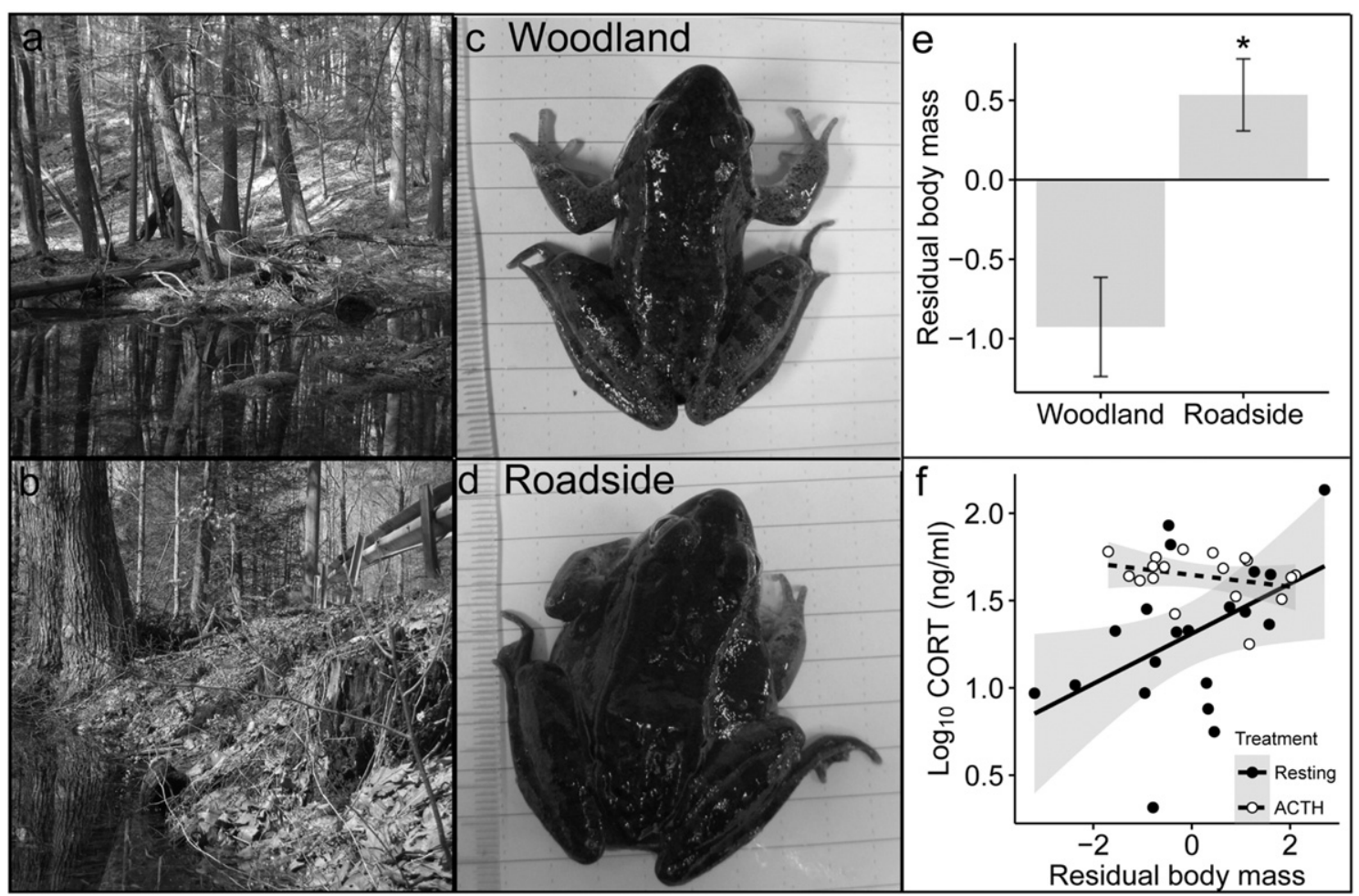

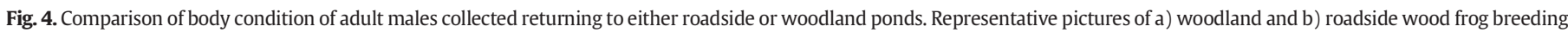

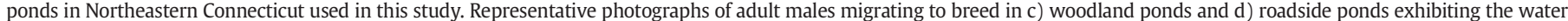

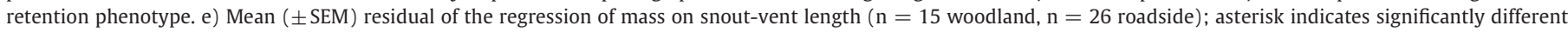

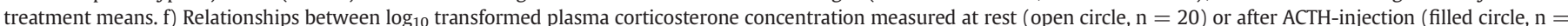

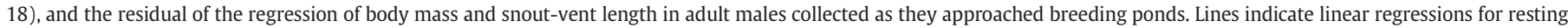
(solid line) and ACTH-induced (dotted line) samples (95\% confidence intervals shaded about lines, interaction effect in mixed model linear regression).

flow to swamp out signals of local adaptation; in more isolated populations, the response to road runoff likely will be more apparent. This finding contrasted the adaptive response observed in populations of the spotted salamander (Ambystoma maculatum) occupying the same breeding ponds used in this study (Brady, 2012), which have a lower tolerance to elevated salinity (Karraker et al., 2008) and reduced movement and gene flow between populations (Richardson, 2012). Thus, we highlight the importance of comparing the response to an environmental stressor across species, as evolutionary and physiological capabilities clearly vary.

The ability of wood frog larvae to tolerate higher salinities came at the expense of body growth in the transplant experiment. Smaller body size in roadside individuals will result in fitness costs later in life, as size at metamorphosis is correlated with survival and reproductive output (Warne and Crespi, 2015; Wilbur and Collins, 1973). Individuals in our experiment appeared to preferentially allocate resources to osmoregulation and maintenance of developmental rate at the cost of growth, as observed when larval wood frogs were challenged with other environmental stressors (Warne and Crespi, 2015). This finding is consistent with other studies testing effects of salinity on larval stages (e.g., Squires et al., 2010), but this is the first report of reduced body length at concentrations below 0.7 ppt. In contrast, Dananay et al. (2015) found larger wood frog larvae in salinized ponds (maximum $430 \mu$ s), potentially due to increased primary productivity (Trombulak and Frissell, 2000; Van Meter et al., 2011) or lower rates of competition due to greater conspecific mortality. Although the standardized conditions within our enclosures allowed us to better isolate physiological effects of elevated salinity, we were unable to measure the effects of ecological factors such as conspecific density on growth in our experiment. To better understand wood frog population level responses to road salt runoff, the carry-over effects of the energetic costs incurred during larval stages needs further study.
Our laboratory experiment suggests that wood frog larvae also alter behavior in response to road salt exposure at relevant concentrations (0.6 ppt salinity). Squires et al. (2008) and Chinathamby et al. (2006) also found decreased larval (Litoria ewingii) activity under elevated salinity conditions ( $>5 \mathrm{ppt}$ ), suggesting that larvae tolerating elevated salinity decrease energy expenditures towards activity behavior in favor of osmoregulatory demands. In contrast to our field experiment, the larvae in our behavioral experiment exhibited slower developmental rates but were larger in body mass. While this also demonstrates an energetic trade-off in elevated-salinity conditions, there might have been environmental factors in natural ponds, such as predation cues, that favored maintaining developmental rates in the field that were not present in laboratory studies. Interestingly, Dananay et al. (2015) also found that road salt exposure slowed development but increased body mass in late-stage wood frog larvae, and they attributed this to higher phytoplankton levels in salt-treated mesocosms. We suggest the increase in mass observed in our experiment was due to increased water retention because feeding behavior was suppressed and food was given ad libitum. Perhaps a combination of factors could result in this development/body mass dynamic, and future studies should examine possible physiological mechanisms.

We also found differences between adult wood frog males migrating to roadside vs. woodland ponds: roadside males had greater body mass residuals, which reflected greater water retention in these animals. These are the first phenotypic effects of elevated salinity from deicing salt runoff reported for adult amphibians. Water retention might be expected when frogs are exposed to hyperosmotic environments such as roadside ponds (Uchiyama and Konno, 2006). However, since these frogs had not yet reached the water when we collected them, exposure to elevated salinity in the terrestrial environment (Findlay and Kelly, 2011) or from previous years breeding in these ponds, may explain this response. In addition, frogs with greater body mass residuals had 
higher resting plasma corticosterone concentrations, similar to ACTHinduced levels of frogs from these same ponds. This association is not surprising since corticosterone and aldosterone, both regulated by the HPI axis, have osmoregulatory functions in amphibians and fishes (McCormick et al., 2013; Uchiyama and Konno, 2006). While this response might be necessary to tolerate high salinity conditions, there could be negative health consequences of chronically elevated corticosterone levels, including a dampened ability to mount a glucocorticoid response to stressors (Breuner et al., 2008; Hu et al., 2008), decreased lifespan, or reduced reproductive output (McEwen and Wingfield, 2003). Chronically elevated glucocorticoids in breeding adults could also alter offspring behavior and physiology (Hu et al., 2008), acting as a potential mechanism of parental environmental effects. Although we only measured males from 2 to 3 ponds of each type, these data support the hypothesis that adults are physiologically affected by exposure to elevated salinity conditions resulting from road runoff.

By looking across life history stages and across a generation, the results from this study provide a more complete picture of the complex biological outcomes associated with road proximity and increased salinity due to road salt runoff. We conclude that the wood frog's embryonic stages are most sensitive to osmotic stress, and that even low to moderate elevations in salinity in roadside ponds pose physiological challenges to larvae and adults that could affect longevity, reproductive output, and stress responsiveness. Even though we did not see mortality during later larval stages, we provide indirect evidence for decreased survival in roadside populations due to the negative consequences of smaller size on juvenile survival (Morey and Reznick, 2001). Further, because breeding adults exhibited reduced capacity of the HPI axis to respond to stimulation, roadside populations will be at a greater risk for declines from additional environmental stressors such as pond drying resulting from climate change or exposure to pathogens, and may serve as sinks in this system. Future research should elucidate the carry-over effects on juvenile and adult fitness in order to provide a complete picture of the physiological effects of this pervasive pollutant. Altogether we provide further support for conservation efforts to focus on monitoring amphibian breeding habitats adjacent to roads and improving guidelines for reduced salt application near these habitats.

\section{Acknowledgements}

We are very grateful for the anonymous reviewers' constructive comments on the manuscript. This work was supported by funding from the National Science Foundation grant [DEB 1011335 to SPB; BCS 1134687 to EJC]; the Mianus River Gorge Preserve Research Assistantship Program, the Yale Carpenter/Sperry/Mellon Fund, the Yale Institute for Biospheric Studies, the Hixon Center for Urban Ecology, the American Museum of Natural History Theodore Roosevelt Fund, and the Federated Garden Club of Connecticut. The Leopold Schepp Foundation supported this work through scholarship. L. Rissler contributed to the conceptual development of the project, and we thank D. Skelly, S. Alonzo, P. Turner, and M. Urban for key guidance and advice. S. Bolden, B. \& H. Brement, J. Burmeister, J. Richardson, S. Attwood, N. Marks, G. Giller, and S. Duncan assisted with field and/or lab work. Thank you J. Busch and D. Grossenbacher for helpful comments on the manuscript.

\section{References}

Anholt, B.R., Werner, E.E., 1998. Predictable changes in predation mortality as a consequence of changes in food availability and predation risk. Evol. Ecol. 12, 729-738.
Bates, D., Maechler, M., Bolker, B., Walker, S., 2015. Fitting linear mixed-effects models using lme4. J. Stat. Softw. 67, 1-48.

Berven, K.A., Grudzien, T.A., 1990. Dispersal in the wood frog (Rana sylvatica): implications for genetic population structure. Evolution 44, 2047-2056.

Bonier, F., Martin, P.R., Moore, I.T., Wingfield, J.C., 2009. Do baseline glucocorticoids predict fitness? Trends Ecol. Evol. 24, 634-642.

Brady, S.P., 2012. Road to evolution? Local adaptation to road adjacency in an amphibian (Ambystoma maculatum). Sci. Report. 2.

Brady, S.P., 2013. Microgeographic maladaptive performance and deme depression in response to roads and runoff. Peer] 1, e163.

Brady, S.P., 2016. Environmental Exposure Does Not Explain Putative Maladaptation in Road-adjacent Populations. (bioRxiv). http://dx.doi.org/10.1101/ 095273.

Breuner, C.W., Patterson, S.H., Hahn, T.P., 2008. In search of relationships between the acute adrenocortical response and fitness. Gen. Comp. Endocrinol. 157, $288-295$.

Chinathamby, K., Reina, R.D., Bailey, P.C., Lees, B.K., 2006. Effects of salinity on the survival, growth and development of tadpoles of the brown tree frog, Litoria ewingii. Aust. J. Zool. 54, 97-105.

Crespi, E.J., Denver, R.J., 2004. Ontogeny of corticotropin-releasing factor effects on locomotion and foraging in the western spadefoot toad (Spea hammondii). Horm. Behav. 46, 399-410.

Crespi, E.J., Williams, T.D., Jessop, T.S., Delehanty, B., 2013. Life history and the ecology of stress: how do glucocorticoid hormones influence life-history variation in animals? Funct. Ecol. 27, 93-106.

Dananay, K.L., Krynak, K.L., Krynak, T.J., Benard, M.F., 2015. Legacy of road salt: apparent positive larval effects counteracted by negative postmetamorphic effects in wood frogs. Environ. Toxicol. Chem. 34, 2417-2424.

Development Core Team, R., 2012. R: A Language and Environment for Statistical Computing. R Foundation for Statistical Computing, Vienna, Austria (Available at http:// www.R-project.org/).

Dulac, J., 2013. Global Land Transport Infrastructure Requirements: Estimating Road and Railway Infrastructure Capacity and Costs to 2050. International Energy Agency.

Earley, R.L., Lu, C.-K., Lee, I.-H., Wong, S.C., Hsu, Y., 2013. s. Front. Zool. 10.

Findlay, S.E.G., Kelly, V.R., 2011. Emerging indirect and long-term road salt effects on ecosystems. Year in Ecology and Conservation Biology, pp. 58-68.

Forman, R.T.T., Alexander, L.E., 1998. Roads and their major ecological effects. Annu. Rev. Ecol. Syst. 207-231.

Fraker, M.E., Hu, F., Cuddapah, V., McCollum, S.A., Relyea, R.A., Hempel, J., Denver, R.J., 2009. Characterization of an alarm pheromone secreted by amphibian tadpoles that induces behavioral inhibition and suppression of the neuroendocrine stress axis. Horm. Behav. 55, 520-529.

Galloway, L.F., 2001. Parental environmental effects on life history in the herbaceous plant Campanula americana. Ecology 82, 2781-2789.

Glennemeier, K.A., Denver, R.J., 2002. Developmental changes in interrenal responsiveness in anuran amphibians. Integr. Comp. Biol. 42, 565-573.

Gomez-Mestre, I., Tejedo, M., 2003. Local adaptation of an anuran amphibian to osmotically stressful environments. Evolution 57, 1889-1899.

Gomez-Mestre, I., Tejedo, M., Ramayo, E., Estepa, J., 2004. Developmental alterations and osmoregulatory physiology of a larval anuran under osmotic stress. Physiol. Biochem. Zool. 77, 267-274.

Gosner, K.L., 1960. A simplified table for staging anuran embryos and larvae with notes on identification. Herpetologica 16, 183-190.

Hadfield, J.D., 2010. MCMC methods for multi-response generalized linear mixed models: the MCMCglmm R package. J. Stat. Softw. 33, 1-22.

Hendry, A.P., Farrugia, T.J., Kinnison, M.T., 2008. Human influences on rates of phenotypic change in wild animal populations. Mol. Ecol. 17, 20-29.

Hopkins, G.R., Brodie, J.E.D., 2015. Occurrence of amphibians in saline habitats: a review and evolutionary perspective. Herpetol. Monogr. 29, 1-27.

Hu, F., Crespi, E.J., Denver, R.J., 2008. Programming neuroendocrine stress axis activity by exposure to glucocorticoids during postembryonic development of the frog, Xenopus laevis. Endocrinology 149, 5470-5481.

Jackson, R.B., Jobbagy, E.G., 2005. From icy roads to salty streams. Proc. Natl. Acad. Sci. U. S. A. $102,14487-14488$.

Karraker, N.E., Gibbs, J.P., Vonesh, J.R., 2008. Impacts of road deicing salt on the demography of vernal pool-breeding amphibians. Ecol. Appl. 18, 724-734.

Kaushal, S.S., Groffman, P.M., Likens, G.E., Belt, K.T., Stack, W.P., Kelly, V.R., Band, L.E., Fisher, G.T., 2005. Increased salinization of fresh water in the northeastern United States. Proc. Natl. Acad. Sci. U. S. A. 102, 13517-13520.

Kearney, B.D., Pell, R.J., Byrne, P.G., Reina, R.D., 2014. Anuran larval developmental plasticity and survival in response to variable salinity of ecologically relevant timing and magnitude. J. Exp. Zool. A Ecol. Genet. Physiol. 321, 541-549.

Kuznetsova, A., Brockhoff, P.B., Christensen, R.H.B., 2013. ImerTest: Tests for Random and Fixed Effects for Linear Mixed Effect Models (Imer Objects of lme4 Package). R Package Version 2.

Martof, B.S., Humphries, R.L., 1959. Geographic variation in the wood frog Rana sylvatica. Am. Midl. Nat. 61, 350-389.

Mattheus, N.M., 2012. Macro-Ecological Patterns of Stress Physiology in Lithobates sylvaticus. (Master's Thesis). University of Alabama, Tuscaloosa.

McCormick, S.D., Farrell, A.P., Brauner, C.J., 2013. Fish Physiology: Euryhaline Fishes: Fish Physiology. Academic Press.

McEwen, B.S., Wingfield, J.C., 2003. The concept of allostasis in biology and biomedicine. Horm. Behav. 43, 2-15.

Morey, S., Reznick, D., 2001. Effects of larval density on postmetamorphic spadefoot toads (Spea hammondii). Ecology 82, 510-522. 
Peacor, S.D., Pfister, C.A., 2006. Experimental and model analyses of the effects of competition on individual size variation in wood frog (Rana sylvatica) tadpoles. J. Anim. Ecol. 75, 990-999.

Rasband, W., 1997-2012. ImageJ. US National Institutes of Health, Bethesda, Maryland (Available at http://imagej.nih.gov/ij/).

Richardson, J.L., 2012. Divergent landscape effects on population connectivity in two cooccurring amphibian species. Molec. Ecol. 21, 4437-4451.

Rolshausen, G., Phillip, D.A.T., Beckles, D.M., Akbari, A., Ghoshal, S., Hamilton, P.B., Tyler, C.R., Scarlett, A.G., Ramnarine, I., Bentzen, P., Hendry, A.P., 2015. Do stressful conditions make adaptation difficult? Guppies in the oil-polluted environments of southern Trinidad. Evol. Appl. 8, 854-870.

Romero, L.M., Dickens, M.J., Cyr, N.E., 2009. The reactive scope model - a new model integrating homeostasis, allostasis, and stress. Horm. Behav. 55, 375-389.

Sanzo, D., Hecnar, S.J., 2006. Effects of road de-icing salt $(\mathrm{NaCl})$ on larval wood frogs (Rana sylvatica). Environ. Pollut. 140, 247-256.

Sih, A., Ferrari, M.C., Harris, D.J., 2011. Evolution and behavioural responses to human-induced rapid environmental change. Evol. Appl. 4, 367-387.

Skelly, D.K., 2004. Microgeographic countergradient variation in the wood frog, Rana sylvatica. Evolution 58, 160-165.

Skelly, D.K., Werner, E.E., 1990. Behavioral and life-historical responses of larval American toads to an odonate predator. Ecology 2313-2322.

Smith-Gill, S.J., Berven, K.A., 1979. Predicting amphibian metamorphosis. Am. Nat. 113, 563-586.
Squires, Z.E., Bailey, P.C., Reina, R.D., Wong, B.B., 2008. Environmental deterioration increases tadpole vulnerability to predation. Biol. Lett. 4, 392-394.

Squires, Z.E., Bailey, P.C., Reina, R.D., Wong, B.B., 2010. Compensatory growth in tadpoles after transient salinity stress. Mar. Freshw. Res. 61, 219-222.

Swierk, L., Graham, S.P., Langkilde, T., 2014. The stress of scramble: sex differences in behavior and physiological stress response in a time-constrained mating system. Behav. Ecol. Sociobiol. 68, 1761-1768.

Tennessen, J.B., Parks, S.E., Langkilde, T., 2014. Traffic noise causes physiological stress and impairs breeding migration behaviour in frogs. Conserv. Physiol. 2, cou032.

Trombulak, S.C., Frissell, C.A., 2000. Review of ecological effects of roads on terrestrial and aquatic communities. Conserv. Biol. 14, 18-30.

Uchiyama, M., Konno, N., 2006. Hormonal regulation of ion and water transport in anuran amphibians. Gen. Comp. Endocrinol. 147, 54-61.

Van Meter, R.J., Swan, C.M., Leips, J., Snodgrass, J.W., 2011. Road salt stress induces nove food web structure and interactions. Wetlands 31, 843-851.

Warne, R.W., Crespi, E.J., 2015. Larval growth rate and sex determine resource allocation and stress responsiveness across life stages in juvenile frogs. J. Exp. Zool. A Ecol Genet. Physiol. 323, 191-201.

Wilbur, H.M., Collins, J.P., 1973. Ecological aspects of amphibian metamorphosis. Science $182,1305-1314$ 